\title{
Improving gross count gamma-ray logging in uranium mining with the NGRS probe
}

\author{
C. Carasco, B. Pérot, J.-L. Ma, H. Toubon, A. Dubille-Auchère
}

\begin{abstract}
AREVA Mines and the Nuclear Measurement Laboratory of CEA Cadarache are collaborating to improve the sensitivity and precision of uranium concentration measurement by means of gamma ray logging. The determination of uranium concentration in boreholes is performed with the Natural Gamma Ray Sonde (NGRS) based on a NaI(TI) scintillation detector. The total gamma count rate is converted into uranium concentration using a calibration coefficient measured in concrete blocks with known uranium concentration in the AREVA Mines calibration facility located in Bessines, France. Until now, to take into account gamma attenuation in a variety of boreholes diameters, tubing materials, diameters and thicknesses, filling fluid densities and compositions, a semi-empirical formula was used to correct the calibration coefficient measured in Bessines facility. In this work, we propose to use Monte Carlo simulations to improve gamma attenuation corrections. To this purpose, the NGRS probe and the calibration measurements in the standard concrete blocks have been modeled with MCNP computer code. The calibration coefficient determined by simulation, $5.3 \mathrm{~s}^{-1}$ ppmu $\mathrm{u}^{-1} \pm 10 \%$, is in good agreement with the one measured in Bessines, $5.2 \mathrm{~s}^{-1}$ ppm $_{\mathrm{U}^{-1}}$. Based on the validated MCNP model, several parametric studies have been performed. For instance, the rock density and chemical composition proved to have a limited impact on the calibration coefficient. However, gamma self-absorption in uranium leads to a nonlinear relationship between count rate and uranium concentration beyond approximately $1 \%$ of uranium weight fraction, the underestimation of the uranium content reaching more than a factor 2.5 for a $50 \%$ uranium weight fraction. Next steps will concern parametric studies with different tubing materials, diameters and thicknesses, as well as different borehole filling fluids representative of real measurement conditions.
\end{abstract}

\section{Index Terms - Uranium mining, NaI(Tl) scintillators, MCNP}

\section{INTRODUCTION}

The detection of gamma rays emitted by ${ }^{238} \mathrm{U}$ and its daughter nuclei is one of the reference method for detecting uranium in borehole. One approach consists in inferring the uranium concentration in boreholes from the total count rate provided by scintillation counters such as $\mathrm{NaI}(\mathrm{Tl})$ detectors. This approach, known as gross count gamma-ray logging [1], requires a calibration coefficient which is usually measured in concrete blocks of well-defined composition with known uranium concentration. However, the measurement conditions

Summary submitted on June $1^{\text {st }}, 2017$.

Cédric Carasco, Bertrand Pérot and Jean-Luc Ma are with CEA, DEN, Cadarache, Nuclear Measurement Laboratory, F-13108 Saint-Paul-lezDurance, France.

Hervé Toubon and Anne Dubille-Auchère are with AREVA Mines, 92053 La Défense (Courbevoie), France. of the calibration coefficient are not always representative of field conditions and corrections of the measured calibration coefficient are needed. This paper reports numerical simulations performed with the MCNP code in view to improve the accuracy of uranium concentration determination in gross count gamma-ray logging.

\section{VALIDATION OF THE MCNP NUMERICAL MODEL}

To assess uranium concentration in boreholes, a GEOVISTA Natural Gamma Ray Sonde (NGRS) [2] equipped with a $\varnothing=2.4 \mathrm{~cm} \times \mathrm{H}=3.9 \mathrm{~cm}$ cylindrical $\mathrm{NaI}(\mathrm{Tl})$ scintillation crystal is used. The uranium concentration is linearly related to the NGRS count rate via a calibration coefficient $K$. In practice, $\mathrm{K}$ is measured using $70 \mathrm{~cm} \times 70 \mathrm{~cm} \times 70 \mathrm{~cm}$ concrete blocks of known uranium concentration, at AREVA Mines calibration facility in Bessines, France.

The calibration measurement geometry presented in Fig. 1 has been modeled with the MCNP Monte Carlo code. Being a reliable and renown photon-neutron transport code, MCNP is already used in the field of uranium logging to model measurement methods involving neutron sources [3] or measurements based on gamma-ray detection [4], this last approach being also manageable with free available codes like GEANT 4 [5]. The modeled concrete blocks have a $1.9 \mathrm{~g} \mathrm{~cm}^{-3}$ density and an isotropic, homogeneously distributed gamma-ray source corresponding to $2906 \mathrm{ppm}$ of uranium, $15.6 \mathrm{ppm}$ of thorium and $3.7 \%$ of potassium. With a $65 \mathrm{keV}$ energy threshold, the calculated reference calibration coefficient is $K_{\text {air }}^{M C N P}=5.3 \mathrm{~s}^{-1} \mathrm{ppm}_{\mathrm{U}}^{-1}$ for a tubeless NGRS probe in the calibration block, with only air filling the borehole (no fluid), which is compatible with the measured reference calibration coefficient: $K_{\text {air }}^{\text {meas }}=5.2 \mathrm{~s}^{-1} \mathrm{ppm}^{-1}$. Measurements with the NGRS probe inside tubes of different thicknesses and nature have also been modeled with MCNP. Table I shows that the calculated tube attenuation corrections match the measurements.
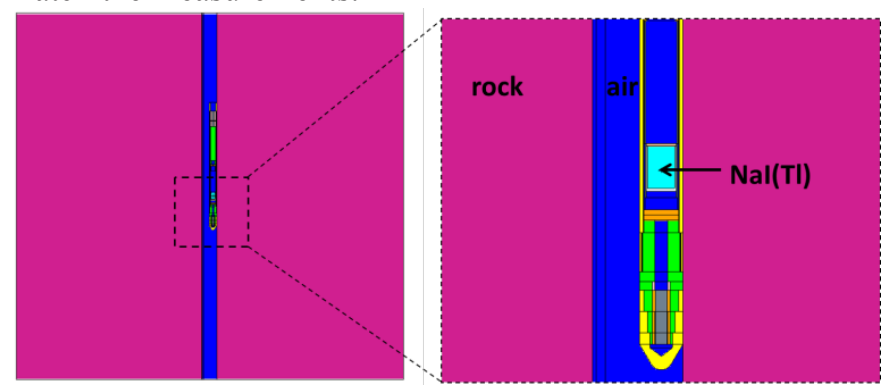

Fig.1. MCNP model of a count rate measurement performed with a NGRS probe positioned inside an air-filled borehole drilled in a $70 \mathrm{~cm} \times 70 \mathrm{~cm} \times 70 \mathrm{~cm}$ calibration concrete block. 
TABLE I. CALCULATED AND MEASURED CALIBRATION COEFFICIENTS KMCNP FOR DIFFERENT TUBES (NATURE AND THICKNESS) AND ATTENUATION CORRECTIONS RELATIVE TO THE TUBELESS CONFIGURATION

\begin{tabular}{|c|c|c|c|c|}
\hline & $\begin{array}{c}\text { No } \\
\text { tube }\end{array}$ & $\begin{array}{c}2 \text { mm thick } \\
\text { Al tube }\end{array}$ & $\begin{array}{c}5 \text { mm thick } \\
\text { Al tube }\end{array}$ & $\begin{array}{c}5 \mathrm{~mm} \text { thick } \\
\text { steel tube }\end{array}$ \\
\hline$K_{\text {tube }}^{M C N P}\left(\mathrm{~s}^{-1} \mathrm{ppmU}^{-1}\right)$ & 5.33 & 5.23 & 5.09 & 3.94 \\
\hline$\frac{K_{\text {air }}^{M C N P}}{K_{\text {tube }}^{M C N P}}$ & 1 & 1.02 & 1.05 & 1.35 \\
\hline$\frac{K_{\text {air }}^{\text {meas }}}{K_{\text {tube }}^{\text {meas }}}$ & 1 & 1.02 & 1.06 & 1.37 \\
\hline
\end{tabular}

\section{SENSITIVITY PARAMETRIC STUDIES}

\section{A. Influence of rock composition}

The impact of the rock mineralogy on the calibration factor has been studied replacing $\mathrm{SiO}_{2}$ with $\mathrm{CaCO}_{3}, \mathrm{CaSO}_{4}-2 \mathrm{H}_{2} \mathrm{O}$ or $\mathrm{Na}_{2} \mathrm{CO}_{3}$. As shown in Table II, rock composition has a small impact on the calibration factor. This lack of sensitivity is caused by the lesser atoms sensitivity of the mass attenuation coefficients when photons have an energy larger than 100 $\mathrm{keV}$.

TABLE II. RATIO OF THE CALCULATED CALIBRATION COEFFICIENTS FOR DIFFERENT ROCK MINERTALOGY AND ENERGY THRESHOLDS

\begin{tabular}{|l|c|c|c|}
\hline Threshold & $\begin{array}{c}\mathrm{CaCO}_{3} \\
\mathrm{~d}=1.6\end{array}$ & $\begin{array}{c}\mathrm{CaSO}_{4}-2 \mathrm{H}_{2} \mathrm{O} \\
\mathrm{d}=1.6\end{array}$ & $\begin{array}{c}\mathrm{Na}_{2} \mathrm{CO}_{3} \\
\mathrm{~d}=1.6\end{array}$ \\
\hline $65 \mathrm{keV}$ & 0.94 & 0.94 & 1.03 \\
\hline $100 \mathrm{keV}$ & 0.96 & 0.96 & 1.02 \\
\hline
\end{tabular}

\section{B. Gamma self-absorption in uranium}

Figure 2 shows calculation results on a wide range of uranium mass fractions, for a NGRS probe inside an iron tube filled with water, located in a $70 \mathrm{~cm}$ edge concrete cube similar to Bessines calibration block. The deviation from the linear fit due to self-attenuation, obtained for uranium mass fractions lower than $1 \%$, begins above uranium $1 \%$, and the selfattenuation effect reaches a factor of 2.6 for $50 \%$ of uranium.

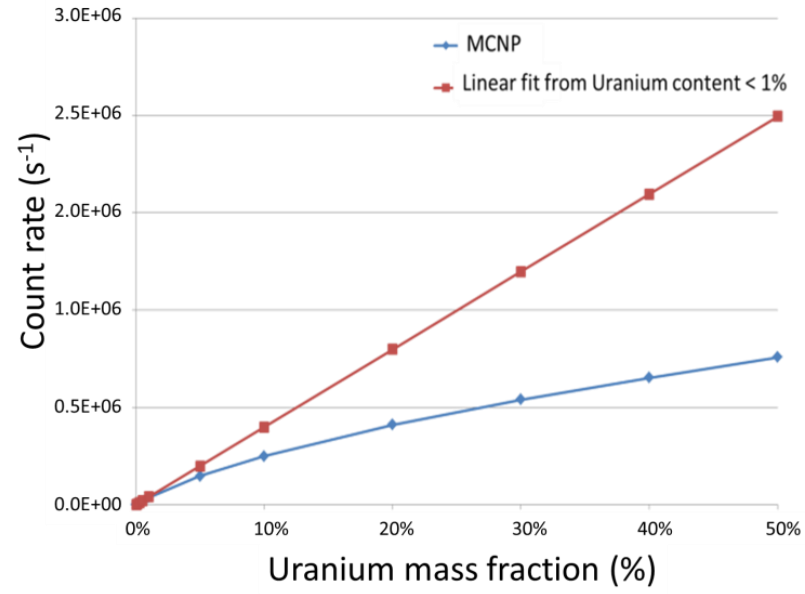

Fig.2. Gamma count rate as a function of uranium mass fraction in a $70 \mathrm{~cm} \times 70 \mathrm{~cm} \times 70 \mathrm{~cm}$ calibration concrete rock.

\section{Gamma range seen by the NGRS probe}

Calculations have been performed to study the range of the gamma rays detected by the NGRS probe, as shown in Fig. 3. The saturation of the signal is reached for a sphere with a radius of about $100 \mathrm{~cm}$. Therefore, we have calculated the calibration coefficient in a concrete block with an edge of $200 \mathrm{~cm}$, instead of $70 \mathrm{~cm}$ for Bessines blocks. The result is $K_{\infty}^{M C N P}=5.8 \mathrm{~s}^{-1} \mathrm{ppm}_{\mathrm{U}}^{-1}$ instead of $5.3 \mathrm{~s}^{-1} \mathrm{ppm}_{\mathrm{U}}^{-1}$, indicating that calibration coefficients measured in Bessines are underestimated by about $10 \%$.

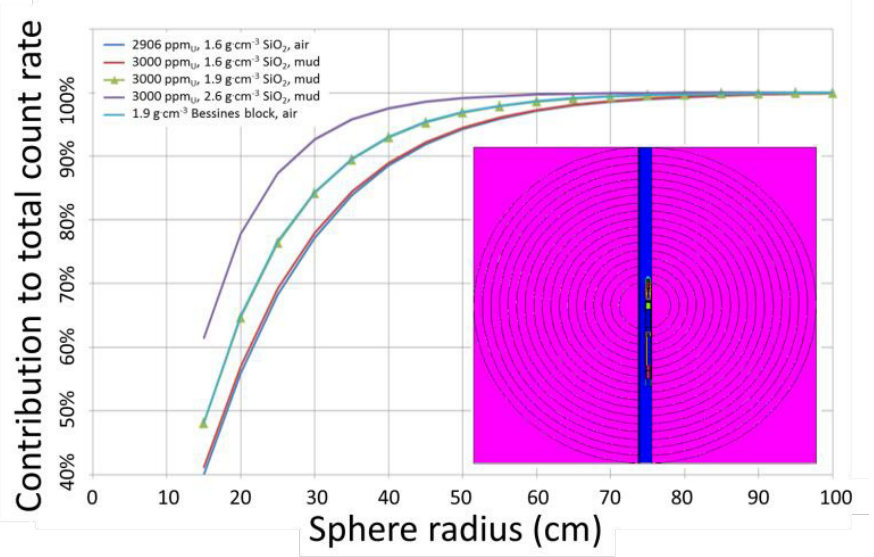

Fig.3. MCNP model and cumulated signal due to uranium present in spheres with an increasing radius for different rocks density and borehole fillings.

\section{D.Influence of rock density}

Calculations with 2906 ppm $_{U}$ have been performed with a 200 cm edge $\mathrm{SiO}_{2}$ block, the reference gamma-ray source, and a tubeless borehole filled with mud (simulated by water with a density of $1.2 \mathrm{~g} \mathrm{~cm}^{-3}$ ), showing that the calibration coefficient slightly decreases from 5.44 to $5.36 \mathrm{~s}^{-1} \mathrm{ppm}_{\mathrm{U}^{-1}}$ when the density varies from 1.2 to $2.6 \mathrm{~g}^{-3} \mathrm{~cm}^{-3}$. Since calculations keep the uranium concentration to 2906 ppm $_{U}$, increasing rock density increases the amount of uranium. The calibration coefficient is therefore poorly sensitive to rock density because the increase of gamma attenuation is compensated by a larger amount of uranium when density rises.

\section{CONCLUSION}

The MCNP Monte Carlo simulation code has been extensively used to model uranium gamma logging with a NGRS probe. MCNP reproduces with a good accuracy the gross gamma counting measurements performed with the $\mathrm{NaI}(\mathrm{Tl})$ gamma scintillator of the probe, such as the calibration coefficient $\mathrm{K}$ $\left(\mathrm{s}^{-1} \cdot \mathrm{ppm}_{\mathrm{U}}^{-1}\right)$ measured in the calibration facility of Bessines, France, which is used to convert the signal $\left(\mathrm{s}^{-1}\right)$ in terms of uranium weight fraction $\left(\mathrm{ppm}_{\mathrm{U}}\right)$ : the coefficient calculated with MCNP is $5.3 \mathrm{~s}^{-1}$ ppm $^{-1} \pm 10 \%$, which is in good agreement with the one measured in Bessines, $5.2 \mathrm{~s}^{-1} \mathrm{ppm}_{\mathrm{U}}^{-1}$.

Sensitivity studies have been performed with MCNP, showing that the rock density and mineralogy have a limited influence on $\mathrm{K}$ coefficient. The uranium concentration induces a significant self-absorption effect above a uranium mass 
fraction of $1 \%$, which leads to an underestimation of the real uranium content up to a factor of 2.6 for $50 \%$ of uranium.

The validated MCNP model will then been used to check the validity of gamma attenuation corrections applied to the reference calibration coefficient measured in Bessines, in a tubeless borehole filled with air, in view of in situ gamma-ray measurements with different fluids filling the borehole and the tube, and with different tubes housing the NGRS probe.

These simulations are the first step of a larger study on uranium gamma logging techniques by CEA and AREVA Mines. Gross count gamma-ray measurement indeed may underestimate the quantity of uranium in case of disequilibrium in the uranium chain due to in situ leaching techniques (roll fronts). For a better assessment of the uranium content, next studies will focus on the use of high energy resolution gamma-ray spectroscopy [6].

\section{REFERENCES}

[1] Practical Borehole Logging Procedures for Mineral Exploration, with Emphasis on Uranium, IAEA Technical Reports Series No. 259 (1986)

[2] http://www.geovista.co.uk/pages/gr-calip.htm

[3] R. P. Gardner, A. Sood, On the future of Monte Carlo simulation for nuclear logs, Applied Radiation and Isotopes 68 (2010) 932-935

[4] D. C. McKeon, Input preprocessor for creating menp models for use in developing large calculational databases, IEEE Transactions On Nuclear Science 41, 1069-1073 (1994).

[5] N. Velker, B. Banzarov, F. Inanc, Al. Vinokurov, N. Simonov, Evaluating Geant4 platform for nuclear well-logging problems, Nucl. Instr. Meth. B 297, 102-109 (2013).

[6] T. Marchais, B. Pérot, C. Carasco, P.-G. Allinei, P. Chaussonet, J-L Ma, H. Toubon, L. Pauthier, Optimization of gamma-ray spectroscopy for uranium mining, ANIMMA 2017, International Conference on Advancements in Nuclear Instrumentation Measurement Methods and their Applications, 19-23 June, Liège, Belgium. 